\title{
Most Admired Companies: Admirable Performance
}

\author{
Vichet Sum ${ }^{1}$
}

\begin{abstract}
This paper shows that most admired companies generate admirable stock performance relative to the market. The current study analyses risk premiums and risk-adjusted excess returns of a portfolio of firms ranked as the most admired companies in the United States from 2006 to 2011. The results show that average risk premiums of an equal-weighted portfolio of most admired firms are economically superior than the market risk premiums from 2006 to 2011 (except 2010). For the 1-year holding period, the portfolio average risk-adjusted excess returns are all positive, but 2010, and some even statistically significant. The portfolio exhibits average positive risk-adjusted excess returns for the 3-year holding period intervals; the alphas are statistically significant for the 2006-2008 period.
\end{abstract}

JEL classification numbers: G11, G12, G14

Keywords: Risk adjusted excess returns, most admired companies, efficient market hypothesis

\section{Introduction}

In the framework of the strong form of the efficient market hypothesis, Fama (1991) posits that all available information, both public and private, should be fully reflected in the security prices so that no one can earn excess returns on a consistent basis. Many researchers have attempted to provide evidence of the stock-picking ability of portfolio managers. Showing that portfolio managers possess the ability to pick stocks to be included in the portfolios that consistently outperform the market portfolio would directly invalidate and humble the proponents of the efficient market hypothesis. Ellis (2000) provides convincing evidence that $89 \%$ of all US-based mutual funds could not beat the S\&P 500 index from 1991 to 2000. Gruber (1996) reveals that average mutual fund

\footnotetext{
${ }^{1}$ University of Maryland - Eastern Shore.

e-mail: vsum@umes.edu

Article Info: Received: July 19, 2012. Revised: September 21, 2012.

Published online : December 20, 2012
} 
underperforms the market portfolio from 1985 to 1994 . Grinblatt and Titman (1992) shows that mutual fund managers possess the ability to pick stocks that beat the market when expenses are not accounted for. Wermers (1997) reports similar findings. Another study conducted by Wermers (2000) shows that the average mutual fund held a stock portfolio that outperforms the market 13 out of 20 years (1975 to 1994) excluding transaction costs. A lack of ability to pick stocks that beat the market portfolio is also empirically documented in the studies conducted by these researchers (Brown \& Goetzmann, 1995; Chang \& Lewellen, 1984; Cumby \& Glen, 1990; Eun, Kolodny, \& Resnick, 1991; Jensen, 1968; Malkiel, 1995).

However, Grinblatt and Titman (1993) offer evidence of abnormal returns net of transaction costs. Chen, Jegadeesh, and Wermers (2000) provide evidence suggesting that mutual fund managers possess superior stock selection skills. Evidence of selectivity ability is also reported by Daniel, et. al. (1997). In an attempt to challenge the efficient market hypothesis, many researchers have compared the performance of a specialized portfolio to the S\&P 500 index's. For instance, Lovisceka \& Jordan (2000) compare the Morningstar's ten-year five-star general equity mutual funds to the S\&P 500 and report that the portfolios tend to outperform the S\&P 500 in the 1990s. Clayman (1987) compares performance of the companies profiled in the Search for Excellence to the S\&P 500 index and finds that 18 of the 29 companies underperform the S\&P 500, yet the other 11 companies outperform the S\&P 500 by 100 basis points per year from 1981 to 1985 . Moreover, another study shows that a portfolio of the most admired companies in the United States outperforms the S\&P 500 by a margin that is substantial and statistically significant from 1983 to 2004 (Anderson \& Smith, 2006). O'Neal (2000) shows that the intermediate-term (3-month to 12-month) top-performing sector funds beat the S\&P 500 index from 1989 to 1999 . Although by a small margin, Staman (2000) shows that a portfolio of socially responsible firms outperforms the S\&P 500 when comparing raw returns from 1990 to 1998. Analyzing stock risk premiums and risk adjusted returns on a portfolio of firms ranked consecutively as the best companies to work for in the United States from 1998 to 2011, Sum (2012) provides evidence that it is possible to construct a portfolio to earn positive average risk premiums and average risk-adjusted excess returns majority of the times. Another study by Sum (2012) examines if a portfolio of firms with the best training program outgains the market index by constructing an equally-weighted portfolio of top 10 companies ranked in the Training Top 125 each year from 2001 to 2010. Sum (2012) reports that 9 out of the 10 portfolios outperform the value-weighted CRSP index by as high as 100 basis points and as low as 11 basis points, and 7 out of the 10 portfolios outperform the S\&P 500 index by as low as 7 basis points and as high as 80 basis points.

The current study is to investigate if a special type of information - being the most admired companies - describing a group of firms is entirely impounded in the firm's stock prices as hypothesized by the efficient market hypothesis. It is the objective of this study to analyze ex-post stock returns of the most admired companies to see if investing in these companies can yield profits that are economically superior than investing in the market portfolio on a consistent basis. In order words, this study is to determine if a portfolio of most admired companies can beat the market on a consistent basis. The current study is relevant and important in the asset pricing and valuation fields, which are ones of the most popularly researched fields in financial economics. The results from this study further our understanding of the various factors affecting stock performance. This study offers important information and implications to the pricing and valuing of stocks. 


\section{Data and Method}

This study constructs an equal-weighted portfolio of publicly-traded companies ranked by Fortune Magazine as the most admired companies in the United States consecutively from 2006 to 2008 and from 2009 to 2011 . For the 2008-2009 periods, the portfolio only consists of publicly traded firms that were ranked consecutively from 2006 to 2008 as the most admired companies; those public firms that were not ranked consecutively from 2006 to 2008 were not included in the construction of the equal-weighted portfolio. Likewise, publicly traded companies that were ranked consecutively from 2009 to 2011 were included in the construction of the equal-weighted portfolio for the 2009-2011 periods. Table 1 shows the names of the companies in the portfolio.

Because the announcement of the most admired companies in the United States is made in March of each year by the Fortune magazine, calculation of the 1-year-holding periods starts in April of each year. For example, for 2006, the calculation includes monthly data from April 2006 to March of 2007. The calculation of the 3-year-holding periods follows the same manner as the 1-year-holding periods. For instance, the 2006-2008 holding period, the calculation includes monthly data from April of 2006 to March of 2009. However, for the 2009-2011, the calculation includes monthly data from April of 2009 to only December of 2011 because the researcher does not have access to monthly data all the way to March of 2012.

The monthly return data are obtained from CRSP database maintained by the University of Chicago accessed through the Wharton Research Data Services at the University of Pennsylvania. The monthly data related to risk-free rate, size, growth, and momentum factors are obtained from Kenneth R. French's data library located at http://mba.tuck.dartmouth.edu/pages/faculty/ken.french/data_library.html.

To compare the portfolio risk premiums to the market risk premiums, equation (1) is used. The single-index model (2) (Sharpe, 1966) and four-factor model (3) (Carhart, 1997) are used to calculate risk-adjusted excess returns on the portfolio.

$$
\begin{gathered}
R_{p t}-R_{f t}=R_{m t}-R_{f t}=R_{S \& P t}-R_{f t} \\
R_{p t}-R_{f t}=\alpha_{1}+\beta_{m}\left(R_{m t}-R_{f t}\right)+\varepsilon_{t 1} \\
R_{p t}-R_{f t}=\alpha_{4}+\beta_{m}\left(R_{m t}-R_{f t}\right)+\beta_{s m b} S M B+\beta_{h m l} H M L \\
+\beta_{m o m} M O M+\varepsilon_{t 4}
\end{gathered}
$$

Where:

$R_{p t}=$ the return on the equal-weighted portfolio in month $t$

$R_{f t}=$ the return on a thirty day T-bill in month $t$

$R_{m t}=$ the return on the CRSP value-weighted index in month $t$

$R_{S \& P t}=$ the return on the S\&P 500 index in month $t$

$S M B=$ the difference between the return on a small-cap portfolio in month $t$ and return on a large-cap portfolio in month $t$

$H M L=$ the difference between return on a high book-to-market (value-stock) portfolio in month $t$ and return on a low book-to-market (growth-stock) 
portfolio in month $t$

$M O M=$ the difference between return on portfolio with higher year (from month -12 to -2 ) return and return on portfolio with lower prior year (from month -12 to -2 ) return

$\alpha_{1}=$ The risk-adjusted excess return on the equal-weighted portfolio from the single-index model

$\alpha_{4}=$ The risk-adjusted excess return on the equal-weighted portfolio from the four-factor model

$\beta_{m}=$ the sensitivity of the excess return on the equal-weighted portfolio to the excess return on the CRSP value-weighted index

$\beta_{s m b}=$ the sensitivity of the excess return on the equal-weighted portfolio to a size factor

$\beta_{h m l}=$ the sensitivity of the excess return on the equal-weighted portfolio to a value factor

$\beta_{\text {mom }}=$ the sensitivity of the excess return on the equal-weighted portfolio to a momentum (hot-hand) factor

$e_{t 1}=$ random error term: excess return on the equal-weighted portfolio in month $t$ not explained by the single-index model

$e_{t 4}=$ random error term: excess return on the equal-weighted portfolio in month $t$ not explained by the four-factor model

\section{Results}

A list of the publicly traded firms ranked as the most admired companies in the United States is shown in Table 1. The portfolio average risk premiums are reported in Table 2. For the 1-year holding period intervals, the average portfolio risk premiums are greater than those of the CRSP value-weighted index by as low as 35 basis points and as high as 88 basis points and outgain the S\&P 500 index by as high as 123 basis points and as low as 53 basis points from 2006 to 2011 (except 2010). The average portfolio risk premiums are all greater than the market risk premiums for the 3 -year-holding period intervals.

Table 1: Most Admired Companies from 2006-2008 and 2009-2011

This list of the most admired publicly traded companies in the United States is obtained from the Fortune Magazine. An equal-weighted portfolio of these companies is formed for the analysis of risk premiums and risk adjusted excess returns reported in this study. 


\begin{tabular}{|c|c|c|c|}
\hline Companies & Ticker & Companies & Ticker \\
\hline \multicolumn{2}{|l|}{ 2006-2008 } & \multicolumn{2}{|l|}{ 2009-2011 (Cont'd) } \\
\hline Alcoa & AA & Goldman Sachs Group & GS \\
\hline Apple & AAPL & Hewlett-Packard & HPQ \\
\hline Abbott Laboratories & $\mathrm{ABT}$ & IBM & IBM \\
\hline Adobe Systems & ADBE & Intel & INTC \\
\hline Aetna & AET & Johnson \& Johnson & JNJ \\
\hline Alaska Air Group & ALK & J.P. Morgan Chase & JPM \\
\hline Allstate & ALL & Nordstrom & JWN \\
\hline AutoNation & $\mathrm{AN}$ & Coca-Cola & $\mathrm{KO}$ \\
\hline Apache & APA & Lowe's & LOW \\
\hline Arrow Electronics & ARW & Southwest Airlines & LUV \\
\hline \multirow{2}{*}{ AT\&T } & $\mathrm{T}$ & Marriott International & MAR \\
\hline & & McDonald's & $\mathrm{MCD}$ \\
\hline \multicolumn{2}{|l|}{$2009-2011$} & $3 \mathrm{M}$ & MMM \\
\hline Apple & AAPL & Microsoft & MSFT \\
\hline American Express & AXP & Nike & NKE \\
\hline Best Buy & BBY & PepsiCo & PEP \\
\hline Caterpillar & CAT & Procter \& Gamble & PG \\
\hline Costco Wholesale & COST & Starbucks & SBUX \\
\hline Cisco Systems & $\mathrm{CSCO}$ & Target & TGT \\
\hline Walt Disney & DIS & UPS & UPS \\
\hline FedEx & FDX & Wells Fargo & WFC \\
\hline General Electric & GE & Wal-Mart Stores & WMT \\
\hline General Mills & GIS & Exxon Mobil & XOM \\
\hline Google & GOOG & & \\
\hline
\end{tabular}

As shown in column 2 and 3 of Table 4, for the 1-year holding period intervals, the portfolio average risk-adjusted excess returns from the single index model are positive 5 out of 6 years; some alphas are even statistically significant. All of the portfolio average risk-adjusted excess returns from the single-index and four-factor models are positive for the 3-year holding period intervals. The alphas are statistically significant for the 2006-2008 holding period.

Table 2: Portfolio Arithmetic Average Risk Premiums and Market Risk Premiums To compare portfolio risk premiums, CRSP value-weighted index and $S \& P 500$ index risk premiums, monthly return data are calculated using equation (1). The portfolio arithmetic average risk premiums, CRSP value-weighted index and $S \& P 500$ index risk premiums are calculated for the 1-year holding and 3-year-holding period intervals. Respective average risk premiums for the portfolio, CRSP value-weighted index and $S \& P$ 500 index are reported in column 2, 3, and 4. The differences in arithmetic averages risk premiums for the portfolio, CRSP value-weighted index and $S \& P 500$ index are reported in column 4 and $5 . \mathrm{Rp}-\mathrm{Rf}=$ average risk premiums of the equal-weighted portfolio; $\mathrm{Rm}$ - $\mathrm{Rf}=C R S P$ value-weighted index average risk premiums; $R_{S \& P}-R_{f}=S \& P 500$ index average risk premiums. 


\begin{tabular}{cccccc}
\hline Years & Rp - Rf & Rm - Rf & Rs\&p - Rf & $\begin{array}{c}\text { (Rp - Rf) } \\
(\mathrm{Rm}-\mathrm{Rf})\end{array}$ & $\begin{array}{c}\text { (Rp - Rf) - } \\
\text { (Rs\&p - Rf) }\end{array}$ \\
\hline 2006 & $1.20 \%$ & $0.54 \%$ & $0.38 \%$ & $0.66 \%$ & $0.82 \%$ \\
2007 & $-0.28 \%$ & $-0.63 \%$ & $-0.86 \%$ & $0.35 \%$ & $0.58 \%$ \\
2008 & $-2.90 \%$ & $-3.78 \%$ & $-3.96 \%$ & $0.88 \%$ & $1.06 \%$ \\
2009 & $4.52 \%$ & $3.75 \%$ & $3.30 \%$ & $0.77 \%$ & $1.23 \%$ \\
2010 & $0.86 \%$ & $1.51 \%$ & $1.17 \%$ & $-0.65 \%$ & $-0.31 \%$ \\
2011 & $0.16 \%$ & $-0.65 \%$ & $-0.47 \%$ & $0.80 \%$ & $0.63 \%$ \\
$2006-2008$ & $-0.66 \%$ & $-1.29 \%$ & $-1.48 \%$ & $0.63 \%$ & $0.82 \%$ \\
$2009-2011$ & $2.00 \%$ & $1.74 \%$ & $1.50 \%$ & $0.26 \%$ & $0.50 \%$ \\
\hline
\end{tabular}

Table 3: Portfolio Geometric Average Risk Premiums and Market Risk Premiums To compare portfolio risk premiums, CRSP value-weighted index and $S \& P 500$ index risk premiums, monthly return data are calculated using equation (1). The geometric average portfolio risk premiums, CRSP value-weighted index and $S \& P 500$ index risk premiums are calculated for the 1-year holding and 3-year-holding period intervals. Respective average risk premiums for the portfolio, CRSP value-weighted index and $S \& P$ 500 index are reported in column 2, 3, and 4. The differences in geometric averages risk premiums for the portfolio, CRSP value-weighted index and $S \& P 500$ index are reported in column 4 and $5 . \mathrm{Rp}-\mathrm{Rf}=$ average risk premiums of the equal-weighted portfolio; $\mathrm{Rm}$ - $\mathrm{Rf}=C R S P$ value-weighted index average risk premiums; $R_{S \& P}-R_{f}=S \& P 500$ index average risk premiums.

\begin{tabular}{cccccc}
\hline Years & Rp - Rf & Rm - Rf & Rs\&p - Rf & $\begin{array}{c}\text { (Rp - Rf) } \\
(\mathrm{Rm}-\mathrm{Rf})\end{array}$ & $\begin{array}{c}\text { (Rp - Rf) - } \\
\text { (Rs\&p - Rf) }\end{array}$ \\
\hline 2006 & $1.15 \%$ & $0.53 \%$ & $.37 \%$ & $0.62 \%$ & $0.78 \%$ \\
2007 & $-0.38 \%$ & $-0.69 \%$ & $-0.91 \%$ & $0.30 \%$ & $0.53 \%$ \\
2008 & $-3.44 \%$ & $-4.08 \%$ & $-4.22 \%$ & $0.64 \%$ & $0.78 \%$ \\
2009 & $4.39 \%$ & $3.67 \%$ & $3.23 \%$ & $0.72 \%$ & $1.16 \%$ \\
2010 & $0.73 \%$ & $1.38 \%$ & $1.04 \%$ & $-0.66 \%$ & $-0.32 \%$ \\
2011 & $0.06 \%$ & $-0.78 \%$ & $-0.59 \%$ & $0.84 \%$ & $0.65 \%$ \\
$2006-2008$ & $-0.91 \%$ & $-1.43 \%$ & $-1.61 \%$ & $0.52 \%$ & $0.70 \%$ \\
$2009-2011$ & $1.86 \%$ & $1.61 \%$ & $1.38 \%$ & $0.25 \%$ & $0.23 \%$ \\
\hline
\end{tabular}

Table 4: Average Portfolio Risk Adjusted Excess Returns

To obtain the portfolio average risk adjusted excess returns (alphas), monthly return data are calculated using equation (2) and (3). The portfolio average risk adjusted excess returns are calculated for the 1-year holding and 3-year-holding period intervals. The portfolio average risk adjusted excess returns from the single-index model are reported in 
column 2. The portfolio average risk adjusted excess returns from the four-factor model are reported in column 3.

\begin{tabular}{ccc}
\hline Years & $\begin{array}{c}\text { Average Risk Adjusted Excess } \\
\text { Returns (alphas) from } \\
\text { the Single-Index Model }\end{array}$ & $\begin{array}{c}\text { Average Risk Adjusted Excess } \\
\text { Returns (alphas) from } \\
\text { the Four-Factor Model }\end{array}$ \\
\hline 2006 & $0.44 \%$ & $1.30 \%$ \\
2007 & $0.64 \% *$ & $0.48 \%$ \\
2008 & $0.96 \%$ & $1.98 \% *$ \\
2009 & $0.14 \%$ & $0.16 \%$ \\
2010 & $-0.64 \%$ & $-1.00 \% * *$ \\
2011 & $0.70 \% * * *$ & $1.06 \% * *$ \\
$2006-2008$ & $0.93 \% * *$ & $0.98 \% * *$ \\
$2009-2011$ & $0.26 \%$ & $0.24 \%$ \\
\hline$* * *$ Significant at 1\% level; ** Significant at 5\% level; * Significant at 10\% level
\end{tabular}

\section{Conclusion}

The current study is to investigate if a special type of information - being the most admired companies - describing a group of firms is entirely impounded in the firm's stock prices as hypothesized by the efficient market hypothesis. It is the objective of this study to analyze ex-post stock returns of the most admired companies to see if investing in these companies can yield profits that are economically superior than investing in the market portfolio on a consistent basis. In order words, this study is to determine if a portfolio of most admired companies can beat the market on a consistent basis. The results show that average risk premiums of an equal-weighted portfolio of most admired firms are economically superior than the market risk premiums from 2006 to 2011 (except 2010). For the 1-year holding period, the portfolio average risk-adjusted excess returns are all positive, but 2010, and some even statistically significant. The portfolio exhibits average positive risk-adjusted excess returns for the 3-year holding period intervals; the alphas are statistically significant for the 2006-2008 period.

This study provides evidence against the efficient market hypothesis which states that all available information, both public and private, should be fully reflected in the security prices so that no one can earn excess returns on a consistent basis. The findings of this study show that a special type of information - being the most admired companies describing a group of firms is not fully reflected in stock prices as hypothesized by the efficient market hypothesis. In addition, the single-index model and four-factor model fail to fully explain variation of returns on a portfolio of most admired firms. The results also suggest that investing in most admired companies can yield average profits which are economically superior than investing in the market portfolio. 


\section{References}

[1] J. Anderson and G. Smith, A great company can be a great investment, Financial Analysts Journal, 62(4), (2006), 86-93.

[2] S. J. Brown and W. N. Goetzmann, Performance persistence, Journal of Finance, 50(2), (1995), 679-98.

[3] M. Carhart, On persistence in mutual fund performance, Journal of Finance, 52, (1997), 57-82.

[4] L. K. C. Chan, N. Jegadeesh and J. Lakonishok, Momentum strategies, Journal of Finance, 51, (1996), 1681-1713.

[5] E. C. Chang and W. G. Lewellen, Market timing and mutual fund investment Performance, Journal of Business, 57(1), (1984), 57-72.

[6] M. Clayman, In search for excellence: The investor's viewpoint, Financial Analysts Journal, 43(3), (1987), 54-63.

[7] R. Cumby and J. D. Glen, Evaluating the performance of international mutual Funds, Journal of Finance, 45(2), (1990), 497-521.

[8] K. Daniel, M. Grinblatt, S. Titman and R. Wermers, Measuring mutual fund performance with characteristic-based benchmarks, Journal of Finance, 52, (1997), 1035-1058.

[9] C. D. Ellis, Levels of the game, Journal of Portfolio Management, 26(2), (2000), 12-15.

[10] C. S. Eun, R. Kolodny and B. G. Resnick, U.S. Based International mutual funds: A performance evaluation, Journal of Portfolio Management, 17(3), (1991), 88-94.

[11] E. F. Fama, Efficient capital markets: II, The Journal of Finance, 46(5), (1991), 1575-1617.

[12] B. Gerhart and G. T. Milkovich, Organizational differences in managerial compensation and firm performance, Academy of Management Journal, 33(4), (1990), 663-691.

[13] M. Grinblatt and S. Titman, The persistence of mutual fund performance, Journal of Finance, 47, (1992), 1977-1984.

[14] M. Grinblatt and S. Titman, Performance measurement without benchmarks: An examination of mutual fund returns, Journal of Business, 66, (1993), 47-68.

[15] M. J. Gruber, Another puzzle: The growth in actively managed mutual funds, Journal of Finance, 51, (1996), 783-810.

[16] M. C. Jensen, The performance of mutual funds in the period 1954-1964, Journal of Finance, 23(2), (1968), 389-416.

[17] A. L. Loviscek and J. W. Jordan, Stock selection based on Morningstar's ten-year, five-star general equity mutual funds, Financial Services Review, 9, (2000), $145-157$.

[18] B. G. Malkiel, Returns from investing in equity mutual funds 1971 to 1991, Journal of Finance, 50(2), (1995), 549-72.

[19] H. M. Markowitz, Portfolio selection, The Journal of Finance, 7(1), (1952), 77-91.

[20] E. S. O'Neal, Industry momentum and sector mutual funds, Financial Analysts Journal, 56(4), (2000), 37-49.

[21] W. F. Sharpe, Mutual fund performance, Journal of Business, 39(1), (1966), 119-138.

[22] M. Statman, Socially responsible mutual funds, Financial Analysts Journal, 56(3), (2000), 30-39. 
[23] V. Sum, Stock performance and the firm's training program, International Research Journal of Applied Finance, 3(5), (2012), 554-559.

[24] V. Sum, Analysis of risk premiums and risk-adjusted excess returns of the best companies to work for in the United States. Unpublished manuscript. Retrieved from http://ssrn.com/abstract $=1950025$

[25] R. Wermers, Mutual fund herding and the impact on stock prices, The Journal of Finance, 54, (1999), 581-622.

[26] R. Wermers, Mutual fund performance: An empirical decomposition into stock-picking talent, style, transactions costs, and expenses, The Journal of Finance, 55(4), (2000), 1655-1703. 